6. A significant relationship was found between dry-matter content of faeces and time of $5 \%$ excretion of stained hay.

7. These results are compared with those found by other workers with goats and also with cattle.

I would like to thank Professor E. G. White, Head of the Department of Veterinary Preventive Medicine, for his kind help and encouragement throughout, and the Agricultural Research Council for a grant which enabled the work to be carried out. My thanks are also due to $\mathrm{Mr} \mathrm{L}$. A. Fairbairn and Mr M. J. R. Healy for help with the statistics and Miss J. E. M. Pyke and Mr J. D. Brewer for their technical assistance.

\title{
REFERENCES
}

Balch, C. C. (I948). Some factors influencing the intake and digestion of food by dairy cows. Ph.D. Thesis, University of Reading.

Balch, C. C. (r950). Brit. F. Nutr. 4, 36r.

Biondo, G. (1953). Nuova Vet. 29, 97.

Brody, S. (x945). Bioenergetics and Growth. New York: Reinhold Publishing Corp.

Columbus, A. (1936). Forschungsdienst, 2, 208.

Ewing, P. V. \& Smith, F. H. (1917). J. agric. Res. 10, 55.

Lenkeit, W. (1930). Tierernähr. u. Tierz. 3, $63 \mathrm{I}$.

Lenkeit, W. (1932). Berl. tierärztl. Wschr. 48, 17 .

Usuelli, F. (1933). Profilassi, 6, 7 .

\section{The effect of penicillin on the thiamine requirement of the rat}

\author{
By M. S. MAMEESH, H. E. SCHENDEL, H. W. NORTON \\ AND B. CONNOR JOHNSON \\ Division of Animal Nutrition, University of Illinois, Urbana, Illinois, U.S.A.
}

(Received 17 September 1955)

Some antibiotics are reported to have a sparing effect on certain B-vitamins when these are deficient in the diet of rats (Lih \& Baumann, r95 I ; Sauberlich, r952; Schendel \& Johnson, I954 $a$; Johnson, Schendel, Hartsook, Batchelor, Promislow \& Cohn, I953): various suggestions have been made as to the mechanism of this action. For example, penicillin may spare thiamine by ( $\mathrm{I}$ ) increasing its absorption from the diet, (2) preventing its bacterial destruction or utilization in the tract or (3) increasing its intestinal synthesis. In any event the net result would be to make more thiamine available to the animal. This increase in available thiamine has been demonstrated by analysing the carcasses and urine of rats on a suboptimal thiamine intake, with or without penicillin (Schendel \& Johnson, I954a). From this finding one might expect a decreased thiamine requirement in the presence of dietary penicillin. The purpose of the experiments reported here was to study this question. 


\section{EXPERIMENTAL}

Weanling male albino rats of the Sprague-Dawley strain were kept individually in wire-bottomed cages. Food and water were given $a d$ lib., daily records of feed intake were kept and the animals were weighed at weekly intervals.

The experimental diet was constituted as follows: sucrose $73 \cdot 0$, vitamin-free casein I $8 \cdot 0$, mineral mixture $44^{6}$ (Schendel \& Johnson, I954b) $4^{\circ} \circ$, maize oil $4^{\circ} \circ$, cholinestarch mixture $(25 \%$ choline) $0.4 \%$. To I $\mathrm{kg}$ of this diet the following vitamins, premixed with $6.0 \mathrm{~g}$ glucose (cerelose), were added: nicotinic acid $100.0 \mathrm{mg}$, riboflavin $16.0 \mathrm{mg}$, pyridoxin hydrochloride $6.0 \mathrm{mg}$, folic acid $4.0 \mathrm{mg}$, biotin $0.6 \mathrm{mg}$, calcium pantothenate $40.0 \mathrm{mg}$, vitamin $\mathrm{B}_{12} 50.0 \mu \mathrm{g}$, vitamin $\mathrm{A} 20,000$ i.u., vitamin $\mathrm{D}$ 2000 i.u., $\alpha$-tocopheryl acetate $r 20 \mathrm{mg}, 2$-methyl-I : 4-naphthoquinone $\mathrm{I} \cdot 0 \mathrm{mg}$.

Five rats were used in each group, and all were on experiment for 4 weeks.

For the animals that received the antibiotic, $50 \mathrm{mg}$ crystalline sodium penicillin $\mathrm{G}$ were mixed with each $\mathrm{kg}$ of diet. The diets were kept in the cold room. Thiamine was administered by pipetting an aqueous solution on to the daily feed. The concentration of each solution was such that $0.5 \mathrm{ml}$./g diet gave the desired level. The solutions were prepared fresh every week and kept in the cold. Thiamine was given in this manner to eliminate losses that occur in synthetic diets on storage (Elvehjem \& Lyman, 1952; Waibel, Bird \& Baumann, 1954). Thus, in a preliminary experiment in which thiamine was incorporated in the diet at several levels, marked growth stimulation was obtained at the lower levels (up to $5 \mu \mathrm{g} / \mathrm{g}$ ), but so much destruction of thiamine occurred during the experiment that an apparent thiamine requirement of $10 \mu \mathrm{g} / \mathrm{g}$ was obtained.

The first experiment was carried out with the thiamine given daily as described and indicated no effect of penicillin on the requirement, although the usual growth stimulation by penicillin was obtained at low thiamine intakes. The number of groups receiving amounts below the requirement level was insufficient to define reliably the slopes of the thiamine dose-response curves. Therefore a second experiment was carried out. In it lower thiamine levels were used in order to define more exactly the slopes of the dose-response curves and their intersections with the horizontal line of optimum growth.

\section{RESULTS}

The plan of the experiments can be seen from Table I. The results quoted therein support the previous reports that penicillin can alleviate thiamine deficiency in the rat. In Exp. 2, rats receiving 0.4 and $0.5 \mu \mathrm{g}$ thiamine/g diet gained twice as much in weight with penicillin in the diet as without it. However, the response to penicillin decreased as the level of thiamine approached that giving maximum growth on this diet, which in this experiment was $\mathrm{I} \pm 0.03 \mu \mathrm{g} / \mathrm{g}$ diet (see Fig. I). At thiamine intakes of $\mathrm{I} \mu \mathrm{g} / \mathrm{g}$ or higher the rats did not respond to penicillin.

It was found by covariance analysis that the regression of final weight on initial weight was $\mathrm{I} \cdot 47 \pm 0.295 \mathrm{~g} / \mathrm{g}$, and it was thought worth while to adjust the observed final weights for differences in initial weight. The adjusted final weights were used in estimating requirements. 
To estimate the requirement, a regression line rising linearly with dose until the requirement is reached and then proceeding horizontally was fitted by the method of least squares to each set of values, and was found to fit satisfactorily (Fig. I). The relationship between responses and the logarithms of doses was found to be non-linear.

For the animals without penicillin the requirement thus calculated was $1 \cdot 00 \pm 0 \cdot 03$, and for the penicillin-fed animals it was $0.98 \pm 0.14 \mu \mathrm{g}$ thiamine/g diet. The standard errors were estimated by least squares.

Table I. Mean initial weights, and weights after 4 weeks, of groups of five rats receiving different levels of thiamine with and without penicillin

Addition to basal diet

First experiment

$0.5 \mu \mathrm{g}$ thiamine/g diet

$0.5 \mu \mathrm{g}$ thiamine/g diet + penicillin

$\mathrm{I} \cdot 0 \mu \mathrm{g}$ thiamine $/ \mathrm{g}$ diet

$\mathrm{I} \cdot \circ \mu \mathrm{g}$ thiamine/g diet + penicillin

I'5 $\mu \mathrm{g}$ thiamine/g diet

I. $5 \mu \mathrm{g}$ thiamine/g diet + penicillin

$2.0 \mu \mathrm{g}$ thiamine/g diet

$2 \cdot 0 \mu \mathrm{g}$ thiamine/g diet + penicillin

$2.5 \mu \mathrm{g}$ thiamine $/ \mathrm{g}$ diet

$2.5 \mu \mathrm{g}$ thiamine/g diet + penicillin

$5.0 \mu \mathrm{g}$ thiamine/g diet

$5.0 \mu \mathrm{g}$ thiamine/g diet + penicillin

Second experiment

$0.4 \mu \mathrm{g}$ thiamine/g diet

$0.4 \mu \mathrm{g}$ thiamine/g diet + penicillin

$0.5 \mu \mathrm{g}$ thiamine/g diet

$0.5 \mu \mathrm{g}$ thiamine/g diet + penicillin

$0.7 \mu \mathrm{g}$ thiamine/g diet

$0.7 \mu \mathrm{g}$ thiamine/g diet + penicillin

$0.8 \mu \mathrm{g}$ thiamine/g diet

$0.8 \mu \mathrm{g}$ thiamine/g diet + penicillin

$\mathrm{I} \cdot 0 \mu \mathrm{g}$ thiamine $/ \mathrm{g}$ diet

$\mathrm{I} \cdot \circ \mu \mathrm{g}$ thiamine/g diet + penicillin

$\mathrm{I} \cdot 5 \mu \mathrm{g}$ thiamine/g diet

$\mathrm{I} \cdot 5 \mu \mathrm{g}$ thiamine/g diet + penicillin

$5.0 \mu \mathrm{g}$ thiamine $/ \mathrm{g}$ diet

$5^{\circ} \circ \mu \mathrm{g}$ thiamine/g diet + penicillin

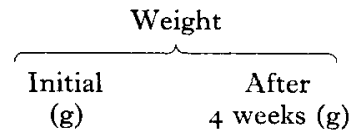

(g) 4 weeks (g)

$\begin{array}{rr}36 & 59 \\ 37 & 108 \\ 37 & 164 \\ 36 & 179 \\ 35 & 186 \\ 37 & 189 \\ 37 & 181 \\ 37 & 191 \\ 36 & 192 \\ 36 & 188 \\ 35 & 187 \\ 38 & 189\end{array}$

83

172

93

180

125

I 96

I 73

I9I

2 II

210

208

200

206

2 I 3

\section{DISCUSSION}

Fig. I shows that with penicillin the growth at the $0.4 \mu \mathrm{g}$ level of thiamine intake equals that at the $0.8 \mu \mathrm{g}$ level without penicillin, i.e. at the lowest level of thiamine intake penicillin produced an effect equivalent to that of $0.4 \mu \mathrm{g}$ thiamine/g diet. At the higher levels of thiamine intake, however, the improvement due to penicillin became less, until on the diet containing I $\mu \mathrm{g}$ thiamine/g diet no improvement resulted from inclusion of penicillin. The several theories that have been put forward to explain the growth-promoting effect of antibiotics added to rations inadequate in certain B-vitamins (see p. 23) all imply that the requirement for dietary thiamine is decreased 
when an antibiotic is included in the diet. It was surprising, therefore, to find in repeated experiments that penicillin did not appreciably affect the amount of dietary thiamine required by rats for optimal performance on this particular diet.

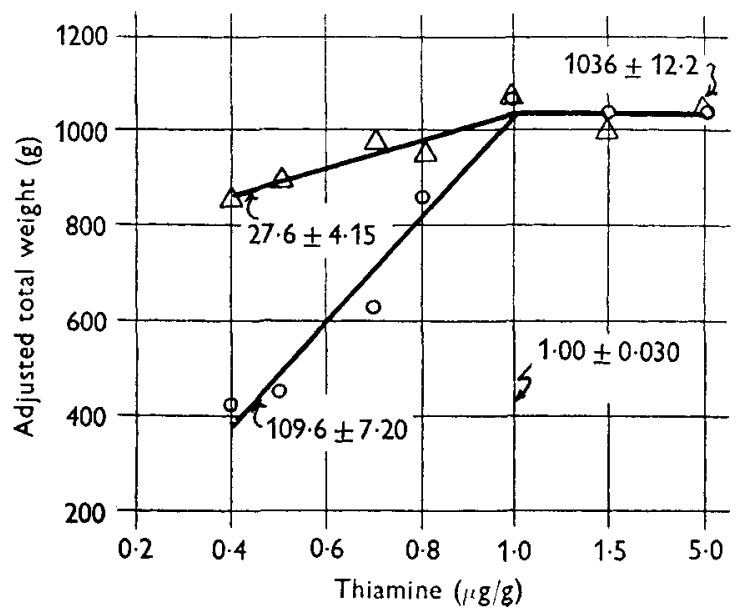

Fig. I. Total adjusted weight (see p. 24) of groups of five rats given different levels of thiamine in the diet. $O$, basal diet; $\triangle$, basal diet with penicillin. The values under the lines give their slope.

To explain these results it is necessary to postulate that thiamine-deficient rats suffer from a condition that limits their ability to utilize efficiently their dietary thiamine. For instance, the absorptive power of the gut might be impaired, either by increase in thickness of the wall (cf. Coates, Davies \& Kon, 1955) or by decreased permeability of the cells; alternatively, a change in microbial flora could result in more or less thiamine being available to the rat. In any event, the condition is apparently overcome by penicillin, and it does not occur in rats given an adequate amount of thiamine in their diet.

\section{SUMMARY}

I. In two experiments groups of five rats were given a thiamine-deficient basal diet supplemented with graded levels of thiamine and with or without penicillin.

2. Whereas penicillin improved the growth of rats given suboptimal levels of thiamine, it did not significantly alter the dietary requirement for thiamine for maximal growth on the diet used.

3. For the rats without penicillin the requirement was $\mathrm{I} \cdot 00 \pm 0.03 \mu \mathrm{g}$ thiamine $/ \mathrm{g}$ diet and for the rats given penicillin it was $0.98 \pm 0.14 \mu \mathrm{g}$ thiamine/g diet.

4. Possible explanations of this unexpected finding are briefly discussed.

\section{REFERENCES}

Coates, M. E., Davies, M. K. \& Kon, S. K. (1955). Brit. F. Nutr. 9, I Io.

Elvehjem, C. A. \& Lyman, R. L. (1952). Nutr. Rev. 10, I34.

Johnson, B. C., Schendel, H. E., Hartsook, E. W., Batchelor, B., Promislow, C. \& Cohn, E. (1953). Abstr. Pap. Amer. chem. Soc. 124th Mtg, p. 26 A. 
Lih, H. \& Baumann, C. A. (1951). F. Nutr. 45, r43.

Sauberlich, H. E. (1952). F. Nutr. 46, 99.

Schendel, H. E. \& Johnson, B. C. (1954a). Fed. Proc. r3, 623.

Schendel, H. E. \& Johnson, B. C. (1954b). F. Nutr. 54, $46 \mathrm{r}$.

Waibel, P. E., Bird, H. R. \& Baumann, C. A. (1954). F. Nutr. 52, 273.

\title{
The use of an electronic computer in the estimation of sampling errors in a nutritional survey
}

\author{
By B. M. CHURCH AND S. LIPTON \\ Rothamsted Experimental Station, Harpenden, Herts
}

(Received 3 October 1955)

If observations covering the whole of a body of material are available, the errors which are to be expected when sampling further material of the same type can be estimated and the relative accuracy of different sampling methods determined. Unfortunately, however, the numerical work required for investigations of this kind is very considerable, and in consequence when only desk machines are available statisticians are often reluctant to undertake this type of investigation with sufficient thoroughness to build up an adequate body of knowledge on sampling errors.

The advent of electronic computers has completely changed the situation, for it is now possible to carry out the required numerical calculations without difficulty. Since work of this kind is essentially repetitive it is eminently suitable for electronic computers, for once a set of instructions (technically known as a programme) appropriate to a particular problem has been written for a machine, further data of the same type can be analysed with little effort.

The present paper deals with the relatively simple but important problem of sampling numerical sequences. The investigation was made in order to determine the number and length of the periods over which an individual's food intake should be observed in order to give sufficiently accurate assessment of the intake of the various dietary components. The nutritional aspects of the investigation and the results are reported by Chappell (1955). Since sampling problems of this type frequently arise in nutritional work and in other fields, it is considered that a brief description of the procedure adopted will be of value. Now that electronic methods of computation are available this type of calculation should become a standard routine when thorough knowledge of sampling errors is required for planning further work.

\section{The problem}

In sampling a numerical sequence we can vary both the size of the sampling unit (here defined as the length of sequence, or number of terms $r$, included in each unit) and the number of such units sampled. Thus in the nutritional problem periods of, for 